\title{
Gender and Energy for Space Heating and Cooling
}

\author{
Prerana Tuladhar \\ Technical Interface \\ Corresponding Email: prerana_tuladhar@yahoo.com
}

\begin{abstract}
:
Energy is one of the crucial aspects now-a-days to be considered from the household chores to the educational, transportation, industrial and many other sectors. Apart from cooking, space heating and cooling also have greater impact as buildings consume about $40 \%$ of world's energy use and major part of energy is used for space heating and cooling [1]. Gender is another aspect that should be taken in to consideration in the energy sector. Discrimination between men and women, either it may be in the knowledge regarding energy sector, profession, application and practices etc. is seen in our society. Therefore, this paper seeks to investigate the impacts of space heating and cooling in the energy consumption pattern of Residential buildings. This paper explores how the gender issues in the energy sector can be addressed and how can it lead towards the sustainable development of the society and then nation. At the same time, paper highlights the changes and improvements in the energy consumption pattern with the enrollment of women in the energy sector. The conclusions are derived from the several literature studies and explorative data analysis with the concern of gender relation with the energy efficiency in the space heating and cooling of residential buildings.
\end{abstract}

Keywords: Gender, Energy, Traditional Building, Modern Building, Space Heating and Cooling

\section{Introduction}

Energy is the basic needs of human-being these days as food, clothes and shelter. Development of the nation is decided as per the energy demand and supply. It is now become necessity for each people and nation to think about the energy and as a result, now various energy efficient devices could be seen in the market. The smart and energy efficient technologies have now developed far better than that of the decades ago. In the past, major focus of people were for their survival i.e. food. Later, they felt the need of clothes to cover their body and then shelter to protect from various natural and environmental problems. In the mid, people focused at their businesses, their effort was to earn more money and fulfill their demands. Now, they have moved towards improving their standard of life with the minimal energy consumption without destructing the nature.

The residential buildings use significantly more energy than commercial buildings (around $70 \%$ of total building sector energy consumption) Currently, around 39\% of $\mathrm{CO} 2$ emissions from the global residential sector are due to space heating and cooling needs [2]. Buildings consume about $40 \%$ of the world's energy use and the major part of energy is used in the building for space heating and cooling [1]. Various study shows that the traditional buildings i.e. with the use of mud mortar, wooden joists etc. has better thermal performance than the modern buildings i.e. with the cement mortar, steel structure, concrete floors etc. According to the [3], the traditional buildings were 1 to $2^{\circ} \mathrm{C}$ warmer in winter and 1 to $2^{\circ} \mathrm{C}$ cooler in summer as compared to modern residential buildings and it saves minimum 10-20\% energy for either heating or cooling both in summer and winter in traditional buildings than modern buildings of Kathmandu.

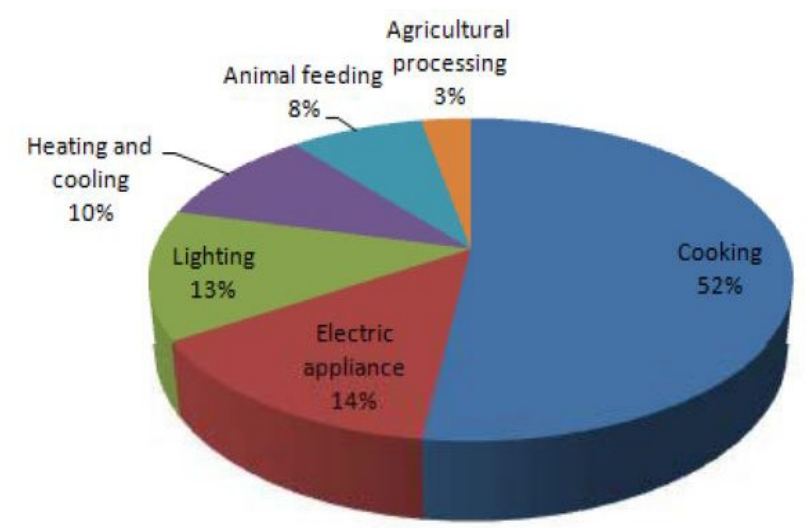

Figure 1: Urban residential sector energy use activities

With the change in time and technology, various changes could be seen from the perspective of gender. Not only the men, but women are also seeming to be participating in various fields such as education, business, transportation, policy and decision-making activities besides household activities. Though, men are considered to be the head of the family, women have high responsibility for the smooth 
running of the house starting from morning breakfast to the late-night dinner, parenting children and domestic family members, taking care of the elders etc. Hence, they have an idea for the proper management and control of house.

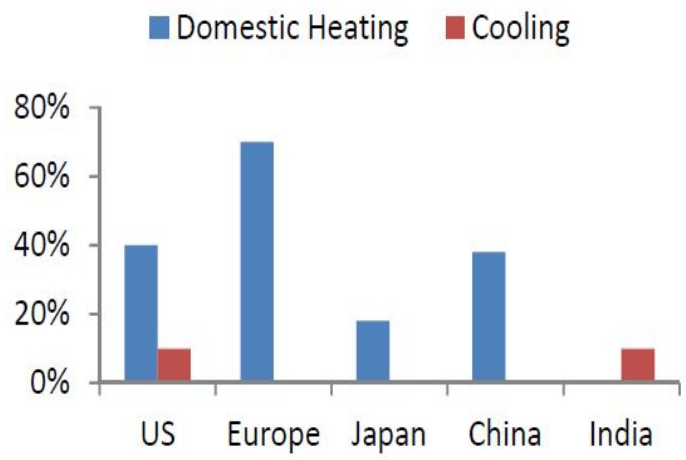

Figure 2: Heating and cooling demand as a percentage of household energy use [2].

\subsection{Research Objective}

This article includes following objectives:

- To study the energy consumption for space heating and cooling for the residential purpose.

- To study the gender roles for the energy efficiency in space heating and cooling.

- To find the gender related solutions for space heating and cooling.

\subsection{Problem Statement:}

It is obvious that the energy consumption for space heating and cooling depends on various factors. Such as: micro-climate, user-behavior, construction material and technology, building design and orientation, local climatic conditions, cultural influences etc. These are the reasons for the impact on energy consumption for space heating and cooling. For the colder climates such as Northern and Central Europe, domestic energy use is dominated by space heating accounting for $60-70 \%$ of residential primary energy consumption as shown in the figure 2 below. Whereas, in the warmer countries like India, cooling is important. The market for heating and/or cooling in developing countries is immature and demand is expected to grow significantly [2].

After cooking, the maximum energy consumption by the activities in residential sector is through water heating and cooling. From the figure 3, it is clear that cooking consumes energy of $61 \%$, space heating and water boiling by $14 \%$ and $13 \%$. Lighting consumes $0.72 \%$, electrical appliances contribute $0.41 \%$ residential energy consumption whereas water pumping contributes only
$0.12 \%$. The other activities share almost $10 \%$ of residential energy consumption. [4].

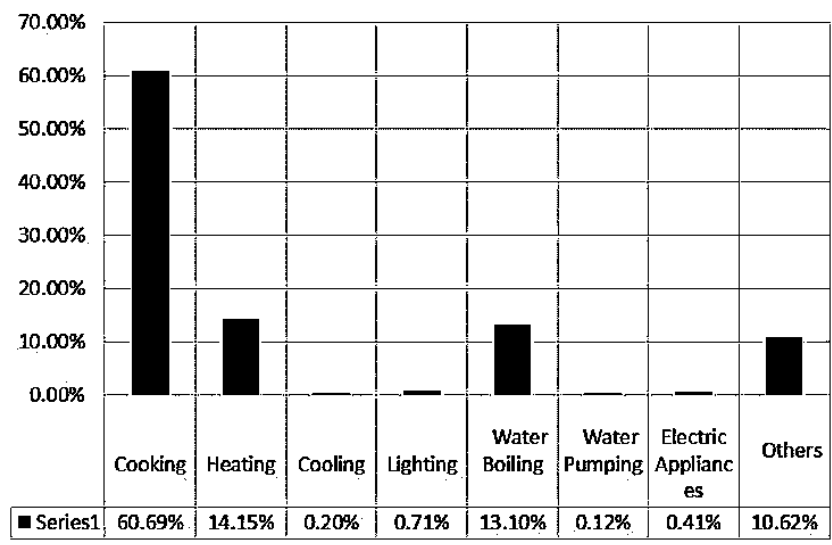

Figure 3: Activities in Residential Energy Consumption [4]

The figure 1, figure 2 and figure 3 shows that heating and cooling of the internal space of the building also requires certain amount of energy which should be taken into consideration.

The strong aftershock in Nepal on $12^{\text {th }}$ May 2015 has caused significant damage to private houses, public infrastructure, and heritage. According to the Ministry of Home Affairs (MoHA), over 604,930 houses were destroyed and 288,856 houses were damaged [5]. Therefore, greater number of traditional houses which has been providing thermal comfort to the people since ancient period are demolished and are being replaced by the modern buildings. Hence, it is necessary to think about the energy consumption by space heating and cooling in residential building.

In our society, women are identified as "homemakers," the keepers of the family, responsible for the well-being of their children and husbands and men as "breadwinners and decision-makers." Beyond this, they are less valued in other energy related fields which are proved by the following statements:

"In our village the women cannot do much. They do agricultural labor, bring fuel wood from the jungle, and look after children". - A man living near Bhopal, India 1997

"Having 10 daughters but no boy is the same as having no children." - Vietnam 1999

Some of the research has been done on environmental attitudes and behavior and gender differences, but the gender differences in energy consumption is an under researched area. According to the [6], "gender sensitive research focusing on energy-saving investment and buying patterns seems to be useful in order to learn more 
Table 1: Households, Population and Buildings damaged of Seven Sectors of Study Area

\begin{tabular}{|l|l|l|l|l|l|l|}
\hline & kV Core & Peri-Urban & Densely Settled & Historical Town & Market Town & Grand Total \\
\hline Total House-holds & 61039 & 3684 & 7438 & 4872 & 3620 & 80653 \\
\hline Owned & 25543 & 1354 & 2408 & 3222 & 2421 & 34948 \\
\hline Rented & 34204 & 2277 & 4874 & 1599 & 1105 & 44059 \\
\hline Population & 258692 & 14081 & 26653 & 19095 & 12634 & 331155 \\
\hline Male & 1346969 & 7348 & 14500 & 10100 & 5998 & 172642 \\
\hline Female & 123995 & 6733 & 12153 & 8995 & 6636 & 158512 \\
\hline Building Damage & 27843 & 1363 & 25 & 5063 & 3793 & 38087 \\
\hline Full & 15120 & 150 & 25 & 3724 & 2360 & 21379 \\
\hline Partial & 12723 & 1213 & & 1339 & 1433 & 16708 \\
\hline
\end{tabular}

about the impact of gender and gender relations on different fields of action such as cooking or heating" Hence, this research is important.

\section{Literature Review}

\subsection{Why gender in energy matters?}

Energy is the major factor in helping women become more productive, independent and empowered. In developing countries, women play a vital role as energy producers and managers of household energy security. Gender roles are assigned to men and women by the society that helps to shape our identity, helps to determine how we are perceived, how we are expected to think and act as women and men.

Gender analysis asks questions, in relation to men and women, about who is doing what, who owns what, who makes decisions about what and how, who gains and losses by a planned intervention etc. Gender analysis is not just only about looking at women alone but in fact, it is about reaching a better understanding of how communities work from the perspective of relationships between men and women. As women and men have different roles, they have different kinds of knowledge and experience of energy, either through their traditional roles, their own non-traditional roles or increasingly as professionals in the energy sector. [7]

Gender relations are socially determined and are influenced by social, cultural, political and economic expectations. Gender roles and relations are made on the basis of an informal arrangement, but if this were a legal matter, it might be called a "contract." [8] Therefore, gender contract is used to describe how the relations between men and women is shaped and enforced. This "contract" is an invisible agreement which determines how men and women should behave.

Gender roles, contracts and relations are not static but change over time as there is vast difference between our mother's generation and us. The changing factors could be education, social factors, economic factors, natural and man-made disasters. Thus, gender roles and relations are generally dynamic and can be renegotiated in response to changed circumstances. They can be encouraged to change and various local, national and international levels are working on it.

\subsection{Need of involving women and men in choosing appropriate technologies and materials}

In any kind of technologies either it may be renewable or non-renewable, women should be also involved because, the technologies may fail for not recognizing women's role as energy managers. Women should be involved in the assessment, choice and adaptation of energy technologies because failure in involving women in the initial testing of new technologies can result in reduced effectiveness for e.g.: improved cooking stoves, in which cooking panes were too small to cook traditional meals. Also, failure to involve women in use, maintenance and or repair of technologies may in long run bring the use of these technologies to halt, particularly if women are the primary users. [7] Similarly, in the case of materials, they should have knowledge regarding the sustainable green materials that are found in the market.

Mainstreaming gender into any kind of projects whether it may be residence or commercial sector, requires an understanding of the importance of considering gender as a critical factor for the project's success and sustainability. 
For e.g.: "the gender assessments in Kazakhstan and Ukraine showed that women are the ones managing household budgets. It is therefore, critical to involve them in consultations to hear their views on energy consumption and energy bill payment given their familiarity and knowledge of household spending. [9].

Women tend to be more receptive to energy efficiency measures. For instance, in Europe, recent studies have shown that single men use up to $25 \%$ more energy than single women and women have been found to be more receptive than men to energy efficiency efforts and more likely to change their behavior to save energy. [10]

\subsubsection{Practical, Productive and Strategic Gender Needs}

In the context of energy, it is necessary to consider three sets of needs or interests: practical needs, productive needs and strategic needs. Practical needs aim to make women's and men's lives easier and more pleasant, but do not challenge the accustomed tasks and roles of women in the household or in society, or their gender relations. Productive needs affect gender relations by improving women's status in the family. Strategic needs are those which relate to women changing their position in society and which help them gain more equality with men and transform gender relations.

\section{Methodology}

This research is explanatory research which focuses on "why gender mainstreaming is essential for the energy sector and how it would help for the energy efficiency in space heating and cooling". The research is based on the Positivism and Constructivism paradigm. As a method, few unstructured interviews and observation was done at Ranipauwa, Mustang. The questionnaires were prepared based on the literature review on the various gender and energy relations.

It was important to collect the field data being "Participant as Observer". This helped to understand the behavior of people in the real context. Case study methodology was followed, where multiple cases are observed and interviewed. While selecting the case, the area with the coldest temperature range i.e. $\left(-2.7^{\circ} \mathrm{C}\right.$ to $\left.-9^{\circ} \mathrm{C}\right)$ and the hottest temperature range i.e. $\left(30^{\circ} \mathrm{C}\right.$ to $\left.35^{\circ} \mathrm{C}\right)$. are chosen.

\subsection{Case study 1: Ranipauwa}

Ranipauwa is the central town of the Mustang district which is $3700 \mathrm{~m}$ above the sea level with the minimum temperature range of $\left(-2.7^{\circ} \mathrm{C}\right.$ t0 $\left.-9^{\circ} \mathrm{C}\right)$ and maximum temperature range of $\left(22^{\circ} \mathrm{C}\right.$ to $\left.26^{\circ} \mathrm{C}\right)$. It is a tourist area providing hotel services as their major business. This could be the reason for the new modern building being dominant over the traditional Mustang architecture.

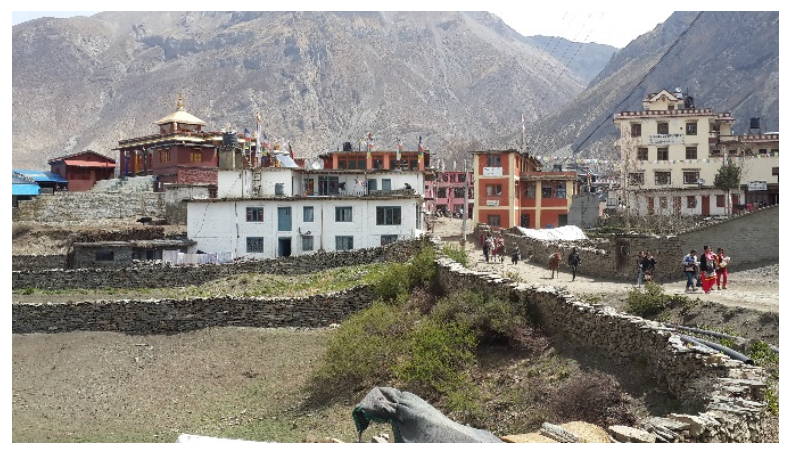

Figure 4: Ranipauwa

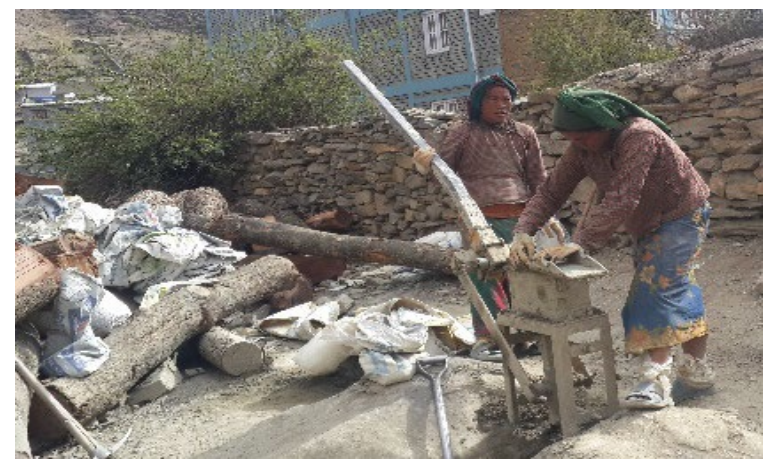

Figure 5: Women making bricks

KNOWLEDGE OF WOMEN IN SPACE HEATING
THROUGH SUSTAINABLE WAYS AT RANIPAUWA

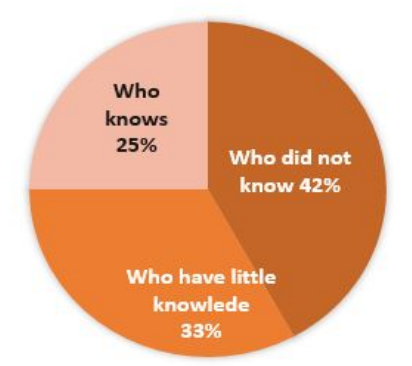

Figure 6: Knowledge of women in space heating through Sustainable ways at Ranipauwa

Study was carried out for finding out the problems regarding space heating and cooling. The room is heated by the gas heaters in the morning and in the evening. They have the central heating system in the kitchen, which is used for boiling the water that dissipates heat inside the room. Hence, it serves as the space for social interaction between the family members. There is a leakage of air inside the room, therefore plastic tapes have been used in order to prevent the cold air to enter inside. Women are seeming to run the hotels more enthusiastically whereas men are busy for their other business at Kathmandu, the core of the city. 
The newly constructed buildings use cement sand mortar with the stone or bricks. However, some building owners are in the process of using their traditional mud "Ghanga" for the construction of new buildings. For the construction of the buildings, women of other nearby village were found to be involved and regarding their labor charge, they say "We are paid less than men". The figure below shows women making bricks out of the local mud available there.

The interview with the local women were taken regarding the knowledge they have for space heating in sustainable ways. The graph shows that $25 \%$ of women knew about the sustainable space heating, 33\% have little knowledge and $42 \%$ of women do not have knowledge.

One of the hotel owners was asked for the reasons of highrise buildings and her answer was "After the earthquake, we have seen most of the traditional buildings being demolished, but the frame structures were not hampered much. So, we find pillars and beam structure are the safest construction. In this type of construction, we can go to the upper structures which also helps our hotel business as the numbers of guest rooms are increased."

After, three days of study with my team, workshop was conducted, where only males participated. We had discussions regarding how to heat the space in sustainable ways. We asked themselves, if they have any idea, their ideas were noted and we put our technological solutions too. The discussion with them brought various possible solutions. For eg: use of straw-mats on the floors, walls and ceiling as an insulation material as similar to the use of carpets in the cold countries on their walls. For this purpose, women can help men in weaving the mats. Plastic bottles, slippers and other worn-out clothes to be used as the insulation material in the ceiling and floors. The passive building design techniques were also shared with them.

\subsection{Case study 2: Putak Village}

Half an hour down from the Ranipauwa is the oldest traditional Putak village. This village is the cluster of traditional houses with the stone and mud bonded thick walls and courtyard space.

The ground floors of these buildings are the space designed for domestic animals and their food storage whereas the upper floors are for living, dining and kitchen. The buildings are double storied. Each residence of the village have traditional chulo, i.e. fuel wood for cooking in their kitchen and the most interesting thing is they have bedroom attached with the kitchen without the partition walls so that the heat could dissipate inside the entire room and they do not have to use extra fuel for heating the room.

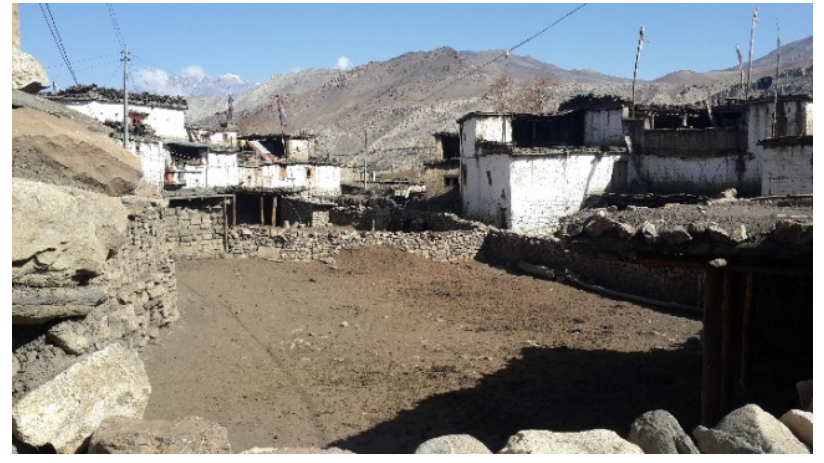

Figure 7: Putak Village

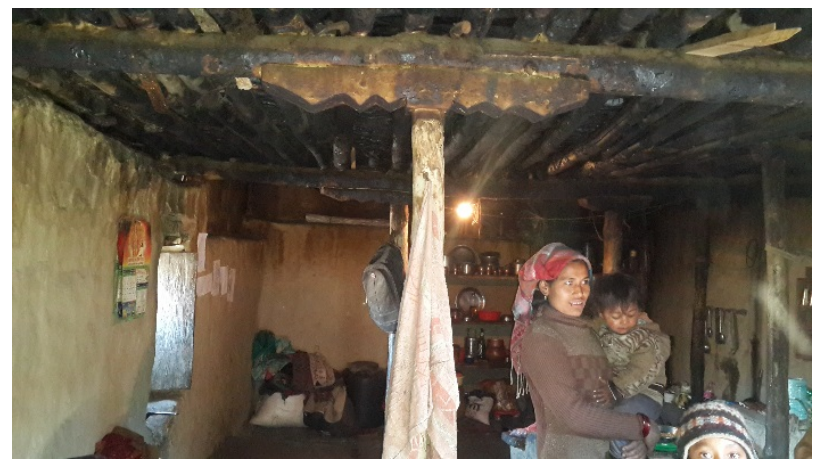

Figure 8: Interior of Putak house

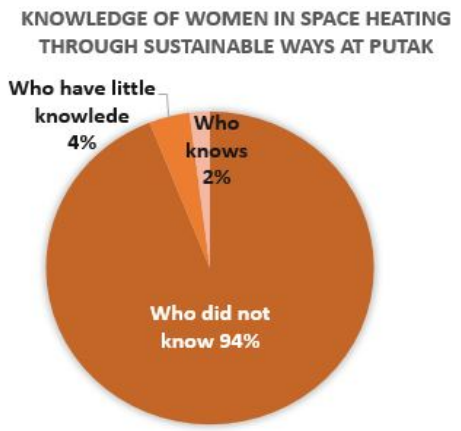

Figure 9: Knowledge of women in space heating through Sustainable ways at Putak

About $90 \%$ collection of fuel wood is done by females of the household, they do agriculture and look after domestic animals, while men go to the Ranipauwa for the purpose of work early in the morning and return in the evening. No such heating devices are used. Women of the Putak village lacks education which was understood when they were asked about the technologies and materials for space heating and cooling.

The graph below shows that $94 \%$ of women knew nothing, $4 \%$ of women have little knowledge and 2\% knew about the sustainable space heating. 


\subsection{Case study 3: Baireni Galchhi}

Baireni-Galchhi is located between the longitude of $27.76^{\circ} \mathrm{N}$ and latitude of $84.98^{\circ} \mathrm{E}$, warm and humid climate. The temperature in summer ranges from $30^{\circ} \mathrm{C}$ to $35^{\circ} \mathrm{C}$ during the day and in the night, it ranges from $25^{\circ} \mathrm{C}$ to $30^{\circ} \mathrm{C}$. [1] The study was conducted along the highway, $441 \mathrm{~m}$ above the sea level. Various construction materials are used such as: hollow concrete blocks with the cement mortar, bricks with the cement or mud mortar, stone with the cement or mud mortar. In some cases, mixed type of buildings is seen, where ground floor is either of stone or brick masonary with mud mortar and the additional floors are of Hollow concrete blocks. Roofs are either concrete flat roofs, traditional jhingati or C.G.I. Use of Hollow concrete blocks are seen prevalently because of the number of factories are there. Most of the women were found to be involved in small hotel business with the chulo outside the building.

After the disastrous earthquake of 2015, the fully demolished traditional buildings are replaced by the modern ones, renovated traditional buildings are replaced by the use of cement sand mortar and the C.G.I. roof. Because of the intolerable heat inside through the C.G.I roof, they have used straw mats on the ceiling as an insulation material. For the construction purpose, women are found to be working as an unskilled labor.

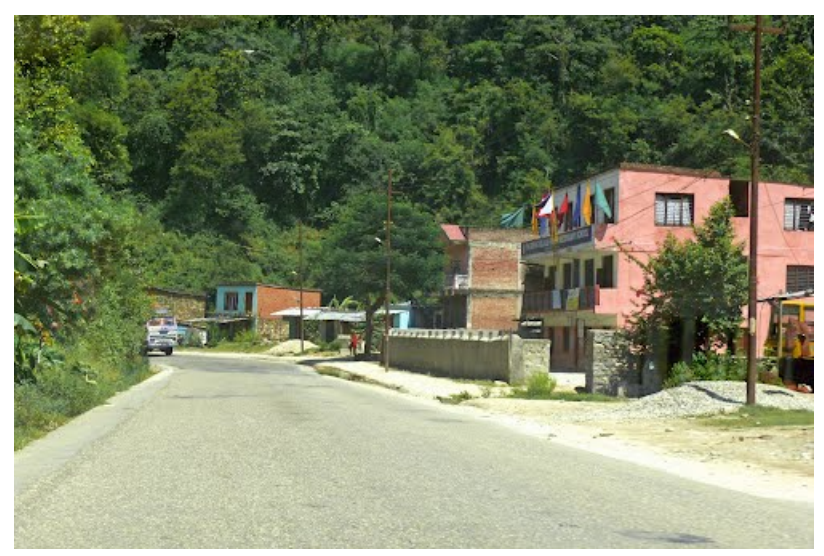

Figure 10: Baireni-Galchhi

In an informal interview, woman was asked why CGI roofs are used massively and how their experience was living under the traditional jhingati roofs and CGI roof. Her answer was "It is very uncomfortable to live under the CGI roof in comparison to the traditional roofs but also we have to choose it because it is light weight, fast and the major thing is it is cheap. After experiencing the

\footnotetext{
${ }^{1}$ Where the wood is used as a fuel for cooking
}

earthquake, we don't want to build the heavy traditional roof again."

The graph below shows that $41 \%$ of people did not know, $24 \%$ of people knew and $35 \%$ of people knew about the sustainable space cooling.

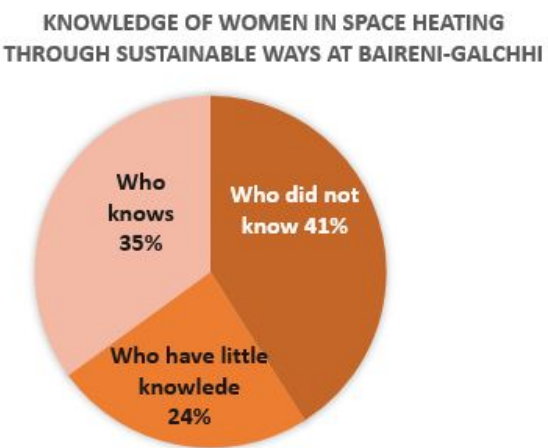

Figure 11: Knowledge of women in space heating through Sustainable ways in Baireni-Galchhi

\section{Findings and Discussion}

The study in three cases shows that women education plays vital role in the field of energy saving. Women of Baireni-Galchhi are found to have more knowledge about the building materials and technology as they are involved in construction field and have the knowledge of Hollow concrete blocks. But, in the case of Ranipauwa, women are more focused towards the hotel business and very few women from nearby village are involved in the construction field. In the case of Putak village, women are given full responsibility regarding household domestic chores. Therefore, they do not get an opportunity to have knowledge on space heating and cooling. However, the traditional houses have been providing them thermal comfort knowingly or unknowingly. Hence, as mentioned in the literature review, Education for women is utmost important. This also proves that practical work and observation helps women learn a lot. One important point is when women are educated, almost all the family members are educated.

Culture, tradition and behavior of people have also greater impact on the thermal comfort of the buildings. Traditional chulo ${ }^{1}$ serves dual purpose: one cooking (primary) and other heating the room (secondary). Hence, this keeps atleast one room warm and where there is warmth, people assemble and social gathering takes place. Similarly, in the Putak village, there is no partition walls between kitchen and bedroom and the size of the room being very small with small ventilation windows, the heat 
from the traditional chulo retains inside the room. But opposite is the case in the Baireni-Galchhi, they have traditional chulo outside the building, this prevents the heat from the chulo to enter inside the building. These are the cultures that have been followed since the ancient times and are also scientific.

Women's knowledge and skills are not applicable until and unless, men value them. For example, men should discuss with the women for the construction of new houses after all she spends much of her time at her home and she is aware of anything that take place inside. Women who are involved in the construction field have much more knowledge about its material and properties and also the technology. Whenever, women know the value of traditional technology and materials, she would not allow the traditional buildings to be replaced by modern buildings.

\section{Conclusion}

The study shows that the second largest energy consumption in the residential building is through space heating and cooling. Therefore, the energy consumption through space heating should not be neglected as it could lead to the energy crisis problem in the near future. From, the three case studies, it is clear that gender relations and roles play an important role. The gender contracts should be changed as per the time and conditions. The three basic needs: practical, productive and strategic needs should be considered and there should be gender equality between men and women. These will solve most of the problems in our society. But it is necessary to have knowledge on the material, technology, culture, tradition etc. that would bring improvement in the sustainable energy consumption in the space heating and cooling.

\section{Acknowledgments}

The author is thankful to all the interviewee for sharing their experience and knowledge. Special thanks to the Master's in Energy for Sustainable Social Development (MSESSD) for the project for the space heating and cooling at Ranipauwa. The author is also grateful for Deputy Director Sangeeta Singh and Dr. Martina M. Keitsch for their valuable suggestion and guidance. Last but not the least, author thanks family and friends who supported me in this work.

\section{References}

[1] P. Tuladhar, S. R. Tiwari and S. B. Bajracharya, "Passive solar approaches for new town development: A case at
Baireni-Galchhi (400-500m)," Proceedings of IOE graduate conference, pp. 439-447, 2017.

[2] E. T. S. A. P. (ETSAP), "Space heating and cooling," 2012.

[3] S. B. Bajracharya, "The thermal performance of traditional residential buildings in Kathmandu valley," Journal of the Institute of Engineering, pp. 172-183.

[4] S. Shrestha and A. M. Nakarmi, "Demand Side Management for Electricity in Nepal: Need analysis using LEAP Modeling Framework," in Proceedings of IOE Graduate Conference, Kathmandu, 2015.

[5] Innovative Solution Pvt.Ltd., "Impact of 2015 Earthquake on housing and livelihoods in urban areas in Nepal," Chakupat,Lalitpur, 2016.

[6] B. Brohman, S. Heinzle, J. Nentwich, U. Offenberger, K. Rennings, K. Schleich and R. Wustenhagen, "Sustainable energy consumption and individual decisions of consumers- reviw of the literature and research needs," University of St. Gallen, Berlin, 2009.

[7] A. V. Rojas, F. M. Schmitt and L. Aguilar, "Guidelines on Renewable Energy Technology for Women in Rural and Informal Urban Areas," Energia, IUCN,Hivos.

[8] Energia, SOPAC and CTA, "The GEnder Face of Energy," 2006.

[9] E. b. f. r. a. development, "Gender Mainstreaming in District heating Projects in the Common wealth of independent states," Climate Investment Funds.

[10] W. bank, "Gender Equality and Energy".

[11] T. W. Schultz, "The value of the Ability to Deal with Disequilibrium," Journal of Economic Literature 13, pp. 827-846, 1975. 